\title{
Increased serum levels of advanced glycation endproducts predict total, cardiovascular and coronary mortality in women with type 2 diabetes: a population-based 18 year follow-up study
}

\author{
B. K. Kilhovd • A. Juutilainen • S. Lehto • \\ T. Rönnemaa • P. A. Torjesen • K. F. Hanssen • \\ M. Laakso
}

Received: 15 November 2006 / Accepted: 13 March 2007 / Published online: 4 May 2007

(C) Springer-Verlag 2007

\begin{abstract}
Aims/hypothesis AGEs, modification products formed by glycation or glycoxidation of proteins and lipids, have been linked to premature atherosclerosis in patients with diabetes. We investigated whether increased serum levels of AGEs
\end{abstract}

B. K. Kilhovd and A. Juutilainen contributed equally to this study.

B. K. Kilhovd • P. A. Torjesen · K. F. Hanssen

Aker and Ullevål Diabetes Research Centre,

Oslo, Norway

B. K. Kilhovd · K. F. Hanssen

Department of Endocrinology, Aker University Hospital,

Faculty of Medicine, University of Oslo,

Oslo, Norway

A. Juutilainen $\cdot$ S. Lehto $\cdot$ M. Laakso $(\bowtie)$

Department of Medicine, University of Kuopio,

70210 Kuopio, Finland

e-mail: markku.laakso@kuh.fi

A. Juutilainen $\cdot$ S. Lehto $\cdot$ M. Laakso

Kuopio University Hospital,

Kuopio, Finland

T. Rönnemaa

Department of Medicine, University of Turku,

Turku, Finland

T. Rönnemaa

Turku University Hospital,

Turku, Finland

P. A. Torjesen

Hormone Laboratory, Aker University Hospital,

Faculty of Medicine, University of Oslo,

Oslo, Norway predict total, cardiovascular (CVD) or CHD mortality in a population-based study.

Subjects and methods Serum levels of AGEs were determined by immunoassay in a random sample of 874 Finnish diabetic study participants (488 men, 386 women), aged 45-64 years. These participants were followed for 18 years for total, CVD and CHD mortality.

Results Multivariate Cox regression models revealed that serum levels of AGEs were significantly associated with total $(p=0.002)$ and CVD mortality $(p=0.021)$ in women, but not in men. Serum levels of AGEs in the highest sexspecific quartile predicted all-cause (hazards ratio [HR] $1.51 ; 95 \%$ confidence intervals [CI], 1.14-1.99; $p=0.004$ ), CVD (HR 1.56; 95\% CI 1.12-2.19; $p=0.009$ ), and CHD (HR 1.68; 95\% CI 1.11-2.52; $p=0.013$ ) mortality in women, even after adjustment for confounding factors, including high-sensitivity C-reactive protein.

Conclusions/interpretation Increased serum levels of AGEs predict total and CVD mortality in women with type 2 diabetes.

Keywords Advanced glycation - Cardiovascular diseases . Coronary disease $\cdot$ Diabetes mellitus $\cdot$ Women

$\begin{array}{ll}\text { Abbreviations } \\ \text { CML } & N^{\varepsilon} \text {-(carboxymethyl)lysine } \\ \text { CVD } & \text { cardiovascular disease } \\ \text { HR } & \text { hazard ratio } \\ \text { hs-CRP } & \text { high-sensitivity C-reactive protein } \\ \text { MI } & \text { myocardial infarction } \\ \text { RAGE } & \text { receptor for AGE }\end{array}$




\section{Introduction}

AGEs are short- and long-term modification products of glycation or glycoxidation of proteins and lipids [1, 2]. They are a heterogeneous group of compounds with multiple biological effects, some of which are mediated by interacting with receptors, including RAGE (the receptor for AGE) on endothelial cells, smooth muscle cells and macrophages [3-5]. Furthermore, AGEs have been identified in atherosclerotic plaques [6]. They are thought to contribute to the development of atherosclerosis by activating the transcription factor NF-KB through RAGE binding, resulting in induction of cellular adhesion molecule expression and cytokine activation [7, 8], or through glycoxidation of lipoproteins and increased foam cell formation [9, 10]. AGEs might also quench nitric oxide activity and mediate impaired endothelial function [11]. Several important AGE compounds have been described, including the glycoxidation and lipoxidation product $N^{\varepsilon}$-(carboxymethyl)lysine (CML) $[2,12]$, which is a ligand for RAGE [13]. Methylglyoxal modification probably represents the major protein modification by glycation in diabetes, and occurs on both intra- and extracellular proteins [14].

Increased AGE modification of long-lived proteins, such as collagen, increases cross-linking and stiffening of arteries [15]. Experimental studies in animals and in humans have shown that treatments that break the crosslinks result in greater vascular compliance [16, 17]. In a cross-sectional study, elevated levels of circulating AGEs correlated with the extent of coronary artery occlusion in type 2 diabetic patients [18]. We recently reported that high serum levels of AGEs predict mortality from CHD in nondiabetic women, but not in non-diabetic men [19].

To date, no prospective follow-up study has been conducted on a large sample of diabetic individuals to examine whether there is a relationship between serum levels of AGEs and the development of cardiovascular complications. Therefore, the aim of the present study was to investigate whether increased serum levels of AGEs predict total, cardiovascular disease (CVD) and CHD mortality in 874 individuals with type 2 diabetes.

\section{Subjects and methods}

Baseline study The study population included 1,059 individuals (581 men, 478 women) with type 2 diabetes, aged 45-64 years, born and living in Kuopio, located in eastern Finland, or in Turku, situated in western Finland. The selection of the study population has been described in detail previously [20]. Study participants with type 1 diabetes were excluded on the basis of the age of onset of diabetes, history of ketoacidosis, and glucagon-stimulated C-peptide measurements at baseline. The present study included 874 participants (488 men, 386 women) with type 2 diabetes whose serum samples were available for the measurement of AGEs.

The study protocol included one outpatient visit to the Clinical Research Unit of the University of Kuopio or the Rehabilitation Research Centre of the Social Insurance Institution in Turku during 1982-1984, as described in detail previously [20]. The visit included an interview on the history of chest pain suggestive of CHD, smoking, alcohol intake, physical activity, and the use of drugs. The medical records of study participants who reported that they had been admitted to hospital for chest pain symptoms were reviewed after careful standardization of the methods between the reviewers in Kuopio (M. Laakso) and Turku (T. Rönnemaa). The WHO criteria for verified definite or possible myocardial infarction (MI), based on chest pain symptoms, ECG changes, and enzyme determinations, were used to define previous MI [21]. A stroke was defined as a definite or possible stroke verified in hospital according to the WHO criteria [22]. Lower extremity amputations for vascular causes were recorded. Prior MI, stroke or lower extremity amputation due to vascular causes were defined as prior CVD.

Smoking status was based on an interview. In all statistical analyses, participants were classified as nonsmokers or current smokers. Blood pressure was measured in the sitting position after a 5 min rest with a mercury sphygmomanometer, and read to the nearest $2 \mathrm{mmHg}$. Participants were classified as having hypertension if they were receiving drug treatment for hypertension or if their systolic blood pressure was at least $160 \mathrm{mmHg}$ or diastolic blood pressure was at least $95 \mathrm{mmHg}$.

At baseline, 273 diabetic men (55.9\%) and 269 diabetic women $(69.7 \%)$ were hypertensive. Diabetes was treated with diet alone in 71 men (14.5\%) and 43 women (11.1\%), with oral hypoglycaemic drugs but not with insulin in 358 men $(73.4 \%)$ and 281 women $(72.8 \%)$, and with insulin in 59 men $(12.1 \%)$ and 61 women $(15.8 \%)$.

All laboratory specimens were drawn at baseline $(08.00 \mathrm{~h})$ after a $12 \mathrm{~h}$ fast, and were subsequently stored frozen at $-20^{\circ} \mathrm{C}$ until analysis. Serum levels of AGEs were measured with a competitive immunoassay developed in our laboratory [23]. Briefly, we used polyclonal anti-AGE antibodies from a rabbit immunised with AGE-RNAse. Europium-labelled anti-rabbit IgG was used as an indicator, and AGE-BSA was used as a standard. Triplicates of the standard or sample together with a fixed amount of antiAGE antibody were added to microtitre plate wells coated with AGE-BSA. The plates were incubated while shaking for $2 \mathrm{~h}$, washed, and then indicating antibodies were added. After a further $1 \mathrm{~h}$ of incubation, europium chelate delayed 
fluorescence was measured. One AGE unit was defined as the displacement activity of $1 \mu \mathrm{g} / \mathrm{ml}$ AGE-BSA standard [24]. The inter-assay coefficient of variation was $15 \%$ for the control in the median range of the assay curve, and $24 \%$ for the control in the lower range. Two batches of antibodies obtained from one animal were used in measurements. Because no significant differences were found between the results obtained in these batches, they were pooled for statistical analyses. No significant differences in baseline characteristics were found between the volunteers who were included in the present study and those who were not, i.e. between those with serum samples available for AGE determination and those without samples available.

Fasting plasma glucose was determined by the glucose oxidase method (Boehringer Mannheim). Serum lipids and lipoproteins were determined from fresh serum samples. Serum total cholesterol (intra-assay variation 1.6\%) and triacylglycerol (intra-assay variation 2.6\%) was assayed by automated enzymatic methods (Boehringer Mannheim, Mannheim, Germany). Serum HDL-cholesterol (intra-assay variation $1.7 \%$ ) was determined enzymatically after precipitation of LDL and VLDL particles with dextran sulphate$\mathrm{MgCl}_{2}$ [25]. LDL-cholesterol was calculated using the Friedewald formula [26]. Total protein concentration (interassay variation $4.5 \%$ ) was measured with the Coomassie Brilliant Blue method (Bio-Rad Laboratories, Hercules, CA, USA). High-sensitivity C-reactive protein (hs-CRP) levels were determined by latex turbidimetric immunoassay (Wako Chemicals, Neuss, Germany). The analytical detection limit of the assay was $3.3 \%$ at the mean level of $1.5 \mathrm{mg} / \mathrm{l}$ and $2.6 \%$ at the mean level of $2.5 \mathrm{mg} / \mathrm{l}$. Serum creatinine was determined by kinetic Jaffé method using a Hitachi 705 analyser (Tokyo, Japan). Creatinine clearance was estimated using the Cockroft-Gault formula $=$ $\{(140$ - age [years] $) \times$ weight $(\mathrm{kg}) \times[1-(0.15 \times \operatorname{sex}$ $\langle$ male $=0 ;$ female $=1\rangle)]\} /(0.814 \times$ serum creatinine $)[27]$.

Follow-up study The follow-up period ended on 1 January 2001. Information on the vital status of the study participants and copies of death certificates of all deceased individuals were obtained from the Cause of Death Register (Statistics Finland, Helsinki, Finland). In the final classification of causes of death, hospital records and autopsy records were used, if available. The causes of death were reviewed by $\mathrm{S}$. Lehto and A. Juutilainen. The endpoints used in this study were all-cause death, non-CVD death, CVD death and CHD death. CVD death was defined by codes 390-459 and CHD death by codes 410-414, based on the International Classification of Diseases, 9th Revision (available from: http://www.who.int/classifications/icd/en/, last accessed in March 2007).

This study was approved by the Ethics Committee of Kuopio University Hospital and the Turku University
Central Hospital. All study participants gave informed consent. The authors had full access to the data and take responsibility for its integrity. All authors have read and agree with the manuscript as written.

Statistical analysis Data analyses were conducted using SPSS 14.0.1 software (SPSS, Chicago, IL, USA). Results for continuous variables are given as means \pm SD or percentages. The bivariate correlation of continuous variables with AGEs was assessed by Spearman's correlation coefficient (with two-tailed significance levels). The differences among the groups were assessed by the $\chi^{2}$ test or the Student's two-tailed $t$ test for independent samples, as appropriate. Univariate and multivariate Cox regression models and Kaplan-Meier survival curves with log rank test statistics were used to investigate the association of cardiovascular risk factors with total, non-CVD, CVD and CHD mortality. In multivariate Cox models, adjustment was made for age, area of residence, sex, BMI, current smoking, hypertension (blood pressure $\geq 160 / 95 \mathrm{mmHg}$ or drug treatment for elevated blood pressure), total cholesterol, triacylglycerol, HDL-cholesterol, total protein, and menopausal status (in women).

\section{Results}

During the 18 year follow-up period, 362 men and 281 women died, including 245 men and 189 women who died of cardiovascular causes. In terms of baseline characteristics of the study participants, compared with men, women were older, had a higher BMI, were more likely to have hypertension, had higher levels of total cholesterol and HDL-cholesterol, total triacylglycerol, lower estimated creatinine clearance, higher fasting plasma glucose, and higher glycated $\mathrm{HbA}_{1}$ (Table 1). Duration of diabetes, ratio of total cholesterol to HDL-cholesterol, and hs-CRP levels were similar in men and women. Men were more often smokers and were more likely to have a history of CVD. Serum AGE level was significantly higher in men than in women.

The prevalence of current smoking and the levels of glycated $\mathrm{HbA}_{1}$, BMI, hs-CRP, fasting plasma glucose, total cholesterol, triacylglycerol and HDL-cholesterol did not differ between the highest sex-specific quartile vs the other quartiles of AGEs. Serum AGE levels were not significantly correlated with age, fasting plasma glucose, glycated $\mathrm{HbA}_{1}$, total cholesterol, HDL-cholesterol, BMI, hs-CRP or creatinine clearance in the study group as a whole (range of correlation from -0.031 to 0.058 ), but it correlated inversely albeit weakly with triacylglycerol $(-0.071, p=0.035)$. The correlation coefficient between AGEs and glycated $\mathrm{HbA}_{1}$ was -0.004 (NS) in men and 0.010 (NS) in women. In women, 
Table 1 Baseline characteristics of the study population

Results are presented as $N, \%$ or means \pm SD

${ }^{\text {a }}$ Difference in means tested after logarithmic transformation

${ }^{\mathrm{b}}$ Estimate from Cockcroft-

Gault formula

\begin{tabular}{llll}
\hline & Men & Women & $p$ value \\
\hline$N$ & 488 & 386 & \\
Age $($ years) & $57.6 \pm 4.9$ & $59.0 \pm 4.9$ & $<0.001$ \\
BMI $\left(\mathrm{kg} / \mathrm{m}^{2}\right.$ ) & $28.3 \pm 4.4$ & $30.3 \pm 5.7$ & $<0.001$ \\
Current smoking (\%) & 25.2 & 6.2 & $<0.001$ \\
Hypertension (\%) & 55.9 & 69.7 & $<0.001$ \\
Previous cardiovascular disease (\%) & 26.2 & 14.8 & $<0.001$ \\
Total cholesterol (mmol/l) & $6.4 \pm 1.4$ & $7.1 \pm 2.0$ & $<0.001$ \\
HDL-cholesterol (mmol/l) & $1.16 \pm 0.33$ & $1.27 \pm 0.38$ & $<0.001$ \\
Ratio of total cholesterol: HDL-cholesterol & $6.0 \pm 2.1$ & $6.1 \pm 3.2$ & 0.345 \\
Triacylglycerol (mmol/l) & $2.4 \pm 1.9$ & $2.9 \pm 3.6$ & 0.001 \\
LDL-cholesterol (mmol/l) & $4.3 \pm 1.2$ & $4.6 \pm 1.3$ & $<0.001$ \\
Creatinine clearance (ml/min) ${ }^{\mathrm{b}}$ & $103 \pm 29$ & $90 \pm 26$ & $<0.001$ \\
Hs-CRP (mg/l) & $3.6 \pm 6.4$ & $4.3 \pm 6.7$ & 0.122 \\
Fasting plasma glucose (mmol/l) & $11.4 \pm 3.8$ & $12.5 \pm 4.1$ & $<0.001$ \\
Glycated HbA $(\%)$ & $9.7 \pm 2.3$ & $10.1 \pm 1.9$ & 0.010 \\
Duration of diabetes (years) & $8.1 \pm 4.2$ & $8.0 \pm 3.9$ & 0.831 \\
Total protein (g/l) & $73.7 \pm 6.2$ & $74.1 \pm 5.9$ & 0.260 \\
AGE (U/ml) & $8.3 \pm 3.9$ & $7.6 \pm 3.6$ & 0.010 \\
\hline
\end{tabular}

the level of AGEs correlated with hs-CRP $(0.123, p=0.022)$, HDL-cholesterol $(0.123, p=0.016)$ and inversely with triacylglycerol $(-0.190, p<0.001)$. Total protein did not correlate with AGEs $(p=-0.025, p=0.473)$. Exclusion of three patients whose serum creatinine was $\geq 200 \mu \mathrm{mol} / \mathrm{l}$ from the statistical analyses did not change the results.

Table 2 gives multiple-adjusted hazard ratios (HRs) for serum AGE levels, as a continuous variable, as a predictor for all-cause, non-CVD, CVD and CHD mortality (Cox

Table 2 Adjusted hazard ratios (95\% CIs) from Cox proportional hazards models for AGEs (per increment of $1 \mathrm{U} / \mathrm{ml}$ ) in relation to total, non-CVD, CVD and CHD mortality during an 18 year follow-up of 488 men and 386 women with type 2 diabetes

\begin{tabular}{lll}
\hline & $\mathrm{HR}^{\mathrm{a}}(95 \% \mathrm{CI})$ & $p$ value \\
\hline Total mortality & & \\
All & $1.02(1.00-1.04)$ & 0.071 \\
Men & $0.99(0.97-1.02)$ & 0.577 \\
Women & $1.05(1.02-1.08)$ & 0.002 \\
Non-CVD mortality & & \\
All & $1.00(0.97-1.04)$ & 0.833 \\
Men & $0.97(0.92-1.02)$ & 0.260 \\
Women & $1.05(1.00-1.11)$ & 0.040 \\
CVD mortality & & \\
All & $1.03(1.00-1.05)$ & 0.043 \\
Men & $1.00(0.97-1.03)$ & 0.876 \\
Women & $1.05(1.01-1.09)$ & 0.021 \\
CHD mortality & & \\
All & $1.02(0.99-1.05)$ & 0.227 \\
Men & $1.00(0.96-1.03)$ & 0.798 \\
Women & $1.04(0.99-1.10)$ & 0.152 \\
\hline
\end{tabular}

${ }^{a}$ Adjusted for age, area of residence, sex (in all), BMI, current smoking, hypertension, total cholesterol, HDL-cholesterol, triacylglycerol, total protein and for menopausal status (in women) regression model). Because AGE levels and sex showed significant interaction in their effects on total mortality ( $p=$ 0.037 for interaction), the results are presented separately for men and women. Adjusted serum AGE levels were significantly related to total $(p=0.002)$, non-CVD $(p=$ $0.040)$ and CVD $(p=0.021)$ mortality in women, but not in men. Of the non-CVD deaths, diabetes-related deaths accounted for $27.4 \%$ in men and $34.8 \%$ in women.

Sex-specific quartiles of AGEs were <5.9, 5.9-7.8, 7.9 10.074 and $\geq 10.075 \mathrm{U} / \mathrm{ml}$ in men, and $<5.3,5.3-7.24,7.25-$ 9.6 and $>9.6 \mathrm{U} / \mathrm{ml}$ in women. Total and CVD mortality per 1,000 person-years during the 18 year follow-up are presented in Fig. 1. The highest quartile of serum AGEs vs the other three quartiles predicted total $(p=0.003)$ and CVD mortality $(p=0.007)$ in women, but not in men.

Compared with women with AGE levels in the lowest three quartiles, in women with AGE concentrations in the highest AGE quartile, mortality from all causes was 1.5 times higher $(p=0.003)$, CVD mortality was 1.6 times higher $(p=0.007)$, and CHD mortality was 1.6 times higher $(p=0.021)$, independently of confounding factors (Table 3$)$. The results remained essentially similar when participants with prior cardiovascular disease were excluded from statistical analyses (Table 3). Cox model regression coefficients for elevated AGE levels (above the cut-off value for the highest quartile) as a risk factor for CVD mortality are shown in Table 4. The results indicate that regression coefficients did not substantially change during the stepwise adjustment procedure; the regression coefficient was negative for men (range from -0.011 to -0.127 ) and positive (range from 0.339 to 0.481 ) for women.

In Kaplan-Meier survival analysis, total $(p=0.009)$ and CVD mortality $(p=0.025)$ were significantly higher in 


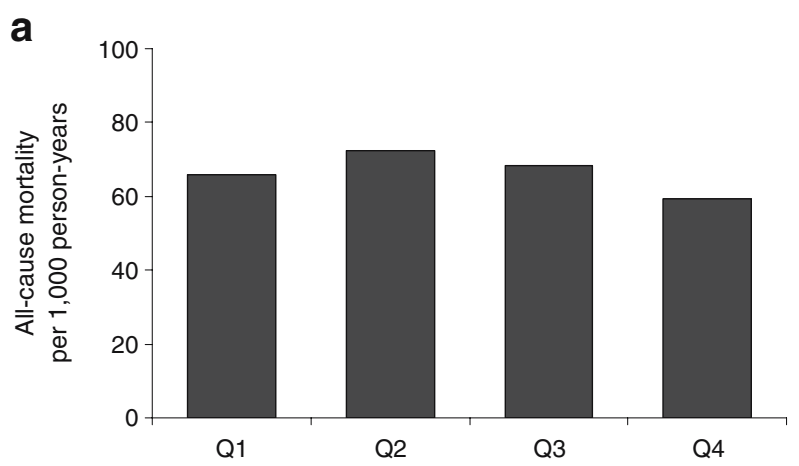

b
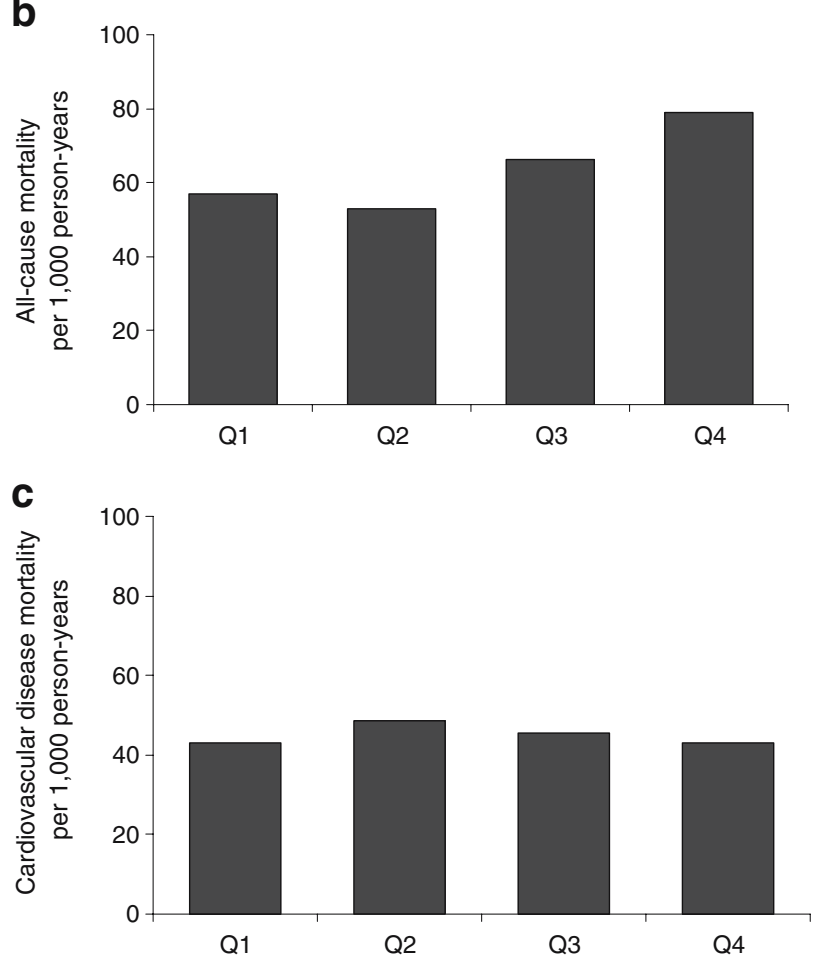

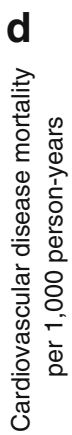

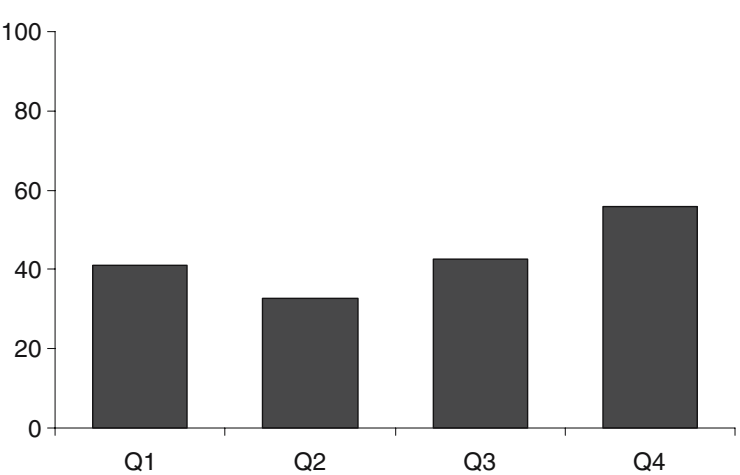

Fig. 1 Total mortality in men (a) and women $(p=0.003)(\mathbf{b})$, and CVD mortality in men (c) and women $(p=0.007)$ (d) per 1,000 person-years during the 18 year follow-up, stratified by sex-specific AGE quartiles (Q1, Q2, Q3, Q4). The $p$ values are for Q4 vs Q1-Q3. The differences in men were not significant women with high AGE levels than in women with low levels of AGEs (with the sex-specific median used as a cutoff point). In men, high AGE levels did not predict total or CVD mortality (Fig. 2).

\section{Discussion}

The present study shows for the first time that increased serum levels of AGEs predict total and CVD mortality in women with type 2 diabetes, and that serum AGE levels in the upper quartile $(\geq 9.6 \mathrm{U} / \mathrm{ml})$ represent an independent risk factor for total and CVD mortality in these study participants.

An increase in skin AGEs can predict progression of diabetic retinopathy and nephropathy in type 1 diabetes [28]. Compared with the use of samples from skin biopsies for measurement of AGEs, serum samples are simple, and with standardisation they could become a useful clinical tool. Previous cross-sectional studies have demonstrated increased serum AGE levels in patients with type 2 diabetes and CVD $[18,29]$. Our study shows that high serum AGE levels predict total, CVD and CHD mortality in type 2 diabetic patients during long-term follow-up. The identification of AGE levels as a predictor of CVD in non-diabetic women in a previous study [19] and in type 2 diabetic women in this study implies that the effect of AGEs on mortality may be independent of diabetes.

Serum AGEs are associated with markers of inflammation [30]. AGE-modified proteins are a heterogeneous group of compounds that are formed through glycation, glycoxidation or, like CML, through glycoxidation/lipoxidation from lipids $[2,12]$. The dominant AGE epitope for binding to the RAGE receptor is CML [13]. Through binding to the RAGE receptor, CML may induce the activation of NF- $\mathrm{KB}$ [13] and increased levels of vascular cell adhesion molecule-1 [31], which might contribute to the development of premature atherosclerosis, although it has been reported that endotoxin-free albumin-derived AGEs are not sufficient to induce RAGE-mediated inflammatory signals [32]. Circulating AGEs may arise from intracellular reactive glucose metabolites [33] or they can be formed in the circulation [34]. Recent studies suggest that the diet could be a source of AGEs [35]. However, in the present study, all participants were fasting. In this study of 874 participants we measured serum AGEs with a polyclonal anti-AGE antibody with the aim of detecting most of the circulating AGEs. The polyclonal anti-AGE antibody has previously been shown to recognise CML as a major antigenic AGE epitope, with $57 \%$ of the variation in serum AGEs explained by variations in serum CML levels [36]. The antibody has also been tested against methylglyoxal-modified BSA, but did not recognise this modified 
Table 3 High serum levels of AGEs as a risk factor for total, non-cardiovascular disease, cardiovascular disease and coronary heart disease mortality in diabetic participants (488 men, 386 women) during an 18 year follow-up in Cox models with two levels of adjustment

\begin{tabular}{|c|c|c|c|c|c|c|c|c|}
\hline & \multicolumn{4}{|l|}{ All participants } & \multicolumn{4}{|c|}{ All participants except those with prior CVD } \\
\hline & \multicolumn{2}{|l|}{ Model 1} & \multicolumn{2}{|l|}{ Model 2} & \multicolumn{2}{|l|}{ Model 1} & \multicolumn{2}{|l|}{ Model 2} \\
\hline & HR $(95 \% \mathrm{CI})$ & $p$ value & $\mathrm{HR}(95 \% \mathrm{CI})$ & $p$ value & HR $(95 \% \mathrm{CI})$ & $p$ value & HR $(95 \% \mathrm{CI})$ & $p$ value \\
\hline \multicolumn{9}{|c|}{ Total mortality } \\
\hline All & $1.11(0.93-1.34)$ & 0.241 & $1.12(0.93-1.36)$ & 0.234 & $1.20(0.97-1.48)$ & 0.089 & $1.21(0.97-1.51)$ & 0.085 \\
\hline Men & $0.85(0.66-1.09)$ & 0.204 & $0.83(0.63-1.08)$ & 0.167 & $0.85(0.63-1.16)$ & 0.315 & $0.83(0.60-1.16)$ & 0.274 \\
\hline Women & $1.49(1.14-1.95)$ & 0.003 & $1.51(1.14-1.99)$ & 0.004 & $1.66(1.24-2.24)$ & 0.001 & $1.70(1.25-2.31)$ & 0.001 \\
\hline \multicolumn{9}{|c|}{ Non-CVD mortality } \\
\hline All & $0.91(0.65-1.27)$ & 0.574 & $0.94(0.65-1.34)$ & 0.716 & $0.97(0.67-1.39)$ & 0.856 & $1.02(0.69-1.50)$ & 0.912 \\
\hline Men & $0.66(0.40-1.08)$ & 0.099 & $0.66(0.39-1.12)$ & 0.127 & $0.72(0.42-1.23)$ & 0.226 & $0.74(0.41-1.32)$ & 0.305 \\
\hline Women & $1.35(0.83-2.18)$ & 0.222 & $1.39(0.84-2.31)$ & 0.197 & $1.55(0.92-2.62)$ & 0.102 & $1.69(0.98-2.89)$ & 0.058 \\
\hline \multicolumn{9}{|c|}{ CVD mortality } \\
\hline All & $1.22(0.98-1.51)$ & 0.070 & $1.21(0.97-1.52)$ & 0.092 & $1.34(1.04-1.73)$ & 0.025 & $1.32(1.01-1.73)$ & 0.042 \\
\hline Men & $0.94(0.70-1.27)$ & 0.684 & $0.90(0.66-1.24)$ & 0.526 & $0.95(0.65-1.38)$ & 0.772 & $0.90(0.61-1.35)$ & 0.618 \\
\hline Women & $1.56(1.13-2.15)$ & 0.007 & $1.56(1.12-2.18)$ & 0.009 & $1.71(1.19-2.45)$ & 0.003 & $1.70(1.17-2.47)$ & 0.005 \\
\hline \multicolumn{9}{|c|}{ CHD mortality } \\
\hline All & $1.18(0.91-1.52)$ & 0.207 & $1.17(0.89-1.52)$ & 0.255 & $1.30(0.96-1.76)$ & 0.090 & $1.28(0.93-1.76)$ & 0.124 \\
\hline Men & $0.84(0.60-1.20)$ & 0.342 & $0.79(0.55-1.14)$ & 0.212 & $0.80(0.51-1.25)$ & 0.325 & $0.72(0.45-1.16)$ & 0.176 \\
\hline Women & $1.59(1.07-2.35)$ & 0.021 & $1.68(1.11-2.52)$ & 0.013 & $1.85(1.20-2.86)$ & 0.005 & $1.95(1.25-3.05)$ & 0.003 \\
\hline
\end{tabular}

Hazard ratios (95\% CIs) are also shown for participants without prior cardiovascular disease at baseline (360 men, 329 women).

Values were calculated for the sex-specific range of AGE levels in the highest quartile vs the range for three lowest quartile; cut-off points of $\geq 10.075 \mathrm{U} / \mathrm{ml}$ in diabetic men and $>9.6 \mathrm{U} / \mathrm{ml}$ in diabetic women were used.

Model 1 adjusted for age, area of residence, sex (in all), total cholesterol, current smoking, hypertension, body mass index, HDL-cholesterol, triacylglycerol, total protein and postmenopausal status (in women).

Model 2 adjusted as for Model 1 plus hs-CRP

protein [37]. The use of newer methods of analysis, such as liquid chromatography tandem mass spectrometry, was not feasible for the large sample studied. This is because only one or a few AGE epitopes can be analysed simultaneously,

Table 4 Cox model regression coefficients $(B)$ for high AGE levels as a risk factor for cardiovascular mortality in 488 diabetic men and 386 diabetic women in stepwise adjustment for other cardiovascular risk factors

\begin{tabular}{|c|c|c|c|}
\hline \multicolumn{2}{|c|}{ Adjustment for } & \multirow{2}{*}{$\begin{array}{l}\text { Men } \\
B \\
-0.011\end{array}$} & \multirow{2}{*}{$\begin{array}{l}\text { Women } \\
B \\
0.339\end{array}$} \\
\hline 1 & Age & & \\
\hline 2 & $1+$ area of residence & -0.070 & 0.339 \\
\hline 3 & $2+$ total cholesterol & -0.099 & 0.399 \\
\hline 4 & $3+$ current smoking & -0.108 & 0.398 \\
\hline 5 & $4+$ hypertension & -0.113 & 0.414 \\
\hline 6 & $5+\mathrm{BMI}$ & -0.114 & 0.415 \\
\hline 7 & $6+$ HDL-cholesterol & -0.125 & 0.481 \\
\hline 8 & $7+$ triacylglycerol & -0.127 & 0.474 \\
\hline 9 & $8+$ total protein & -0.077 & 0.445 \\
\hline 10 & $9+$ postmenopausal status (in women) & -0.077 & 0.446 \\
\hline 11 & $10+$ hs-CRP & -0.105 & 0.444 \\
\hline
\end{tabular}

Values were calculated for the sex-specific range of AGE levels in the highest quartile vs the range for three lowest quartile; cut-off points of $\geq 10.075 \mathrm{U} / \mathrm{ml}$ in diabetic men and $>9.6 \mathrm{U} / \mathrm{ml}$ in diabetic women were used. making the process very time consuming. However, methods are being compared in an ongoing separate project, the results of which will be presented at a later stage.

In the present study, fasting serum AGE levels in the highest quartile ( $\geq 9.6 \mathrm{U} / \mathrm{ml}$ ) were an independent predictor of total, CVD, and CHD mortality in women. In diabetic women, compared with diabetic men, a larger proportion of cardiovascular risk is due to diabetes itself [38]. In line with this notion, elevated levels of AGEs, particularly in women, might reflect an increase in inflammation or oxidative stress in atherosclerosis, since the anti-AGE antibody used recognises the oxidatively modified proteins as well as the glucose-modified compounds. Because high AGE levels predicted mortality even after adjustment for hs-CRP, our results indicate that AGEs also increase mortality independently of inflammation in the vascular wall. Increased AGE levels did not predict atherosclerotic events in men. The difference between men and women in our results could be explained at least in part by a more deleterious effect of glucose and its modification products on vessels in women than in men, as indicated by the finding of a higher proportion of CVD risk being due to diabetes itself in women [38]. The lack of an association between serum AGE levels and CVD in men might also be due to different 
Fig. 2 Kaplan-Meier estimates of survival for total and cardiovascular disease $(C V D)$ mortality according to the sex-specific medians of AGE levels in 488 men and in 386 women with type 2 diabetes during the 18 year follow-up. The dotted lines denote participants with AGE levels above the sex-specific median and the solid lines denote participants with AGE levels below this value. The $p$ values are from $\log$ rank tests. The graphs show total mortality in men $(p=0.448)(\mathbf{a})$, total mortality in women $(p=0.009)$ (b), CVD mortality in men ( $p=$ $0.772)$ (c) and CVD mortality in women $(p=0.025)(\mathbf{d})$ a

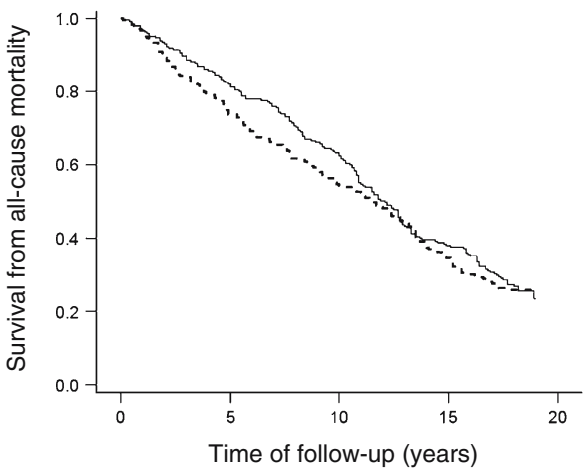

C

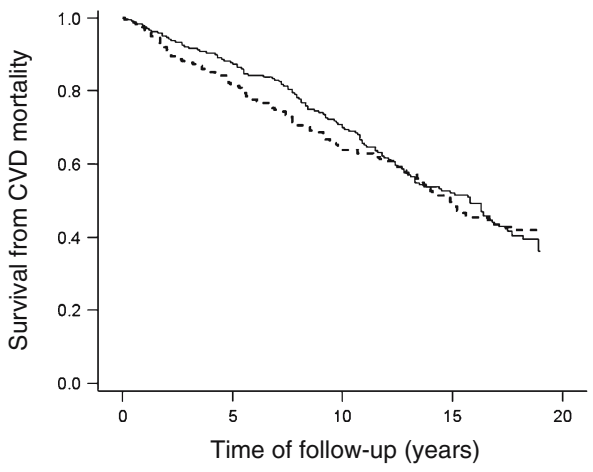

b

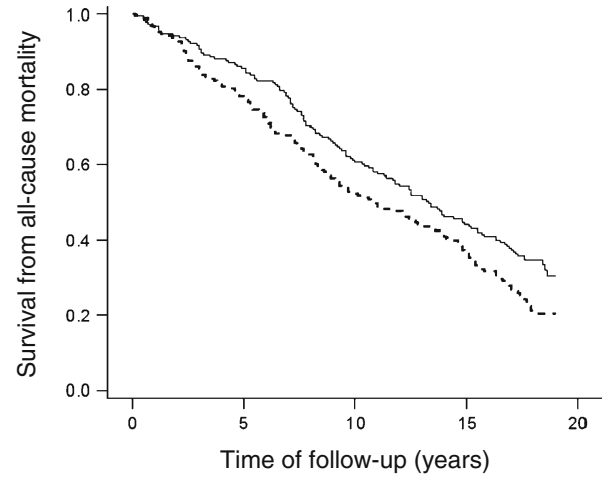

d

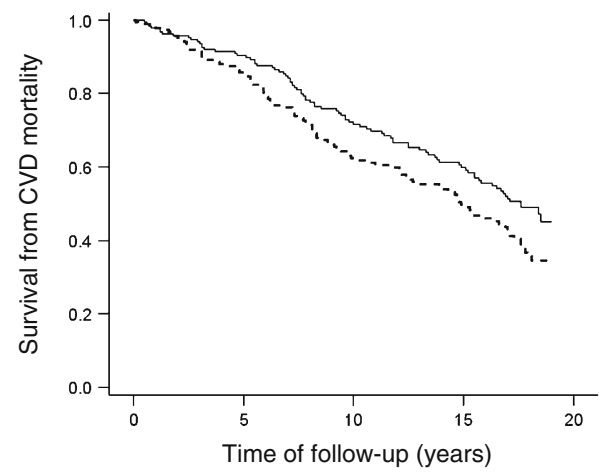

modification of proteins in men and women, but to date no study has compared serum levels of different AGE compounds between the sexes.

Our results suggest that elevated circulating levels of AGEs represent an additional risk factor for atherosclerotic complications in diabetic women. Further studies, including therapeutic studies with AGE-lowering compounds, are needed to substantiate this conclusion. In short-term studies, a decrease in dietary AGEs has been shown to reduce levels of inflammatory mediators such as peripheral blood mononuclear cell TNF- $\alpha$ and hs-CRP [39], as well as glycoxidised LDL [35]. It has been shown that hs-CRP is an independent risk factor for CHD mortality not only in non-diabetic individuals [40], but also in patients with type 2 diabetes [41]. This suggests that inflammation plays an important role in fatal CHD events in this high-risk population.

Serum AGE levels were not significantly correlated with fasting plasma glucose or glycated $\mathrm{HbA}_{1}$ in our study. This may reflect the fact that the anti-AGE antibody recognises the compounds formed by extensive modification of lipids or protein by glucose, as well as the oxidatively modified proteins. Furthermore, the antibody used in the assay recognises CML, which can be formed from both glucose and lipid modification of proteins. Several other studies have also reported a lack of correlation between serum AGEs and plasma glucose or $\mathrm{HbA}_{1 \mathrm{c}}$ using this antibody $[30,36]$. In addition, serum AGE levels can probably be influenced by the turnover of degradation products from previously formed AGEs, and the rate of turnover is not necessarily linked to glucose level.

There are limitations to the present study. The relatively high inter-assay coefficient of variation may underestimate the full aetiological contribution of increased serum AGE levels in atherosclerosis development. Furthermore, degradation of AGE compounds during long-term freezing of serum samples at $-20^{\circ} \mathrm{C}$ could have an effect on measured levels of serum AGEs and possibly obscure weaker associations, including any with glycated $\mathrm{HbA}_{1}$. However, all samples were stored under identical conditions, and so differences in AGE levels should represent differences that were present in the samples when they were drawn. It is unlikely that storage had a different effect on serum AGE levels among survivors and non-survivors. The analytic work was performed by staff unaware of the mortality status of the participants.

In summary, we have shown for the first time that high serum levels of AGEs predict total, CVD and CHD mortality in women with type 2 diabetes. Therefore, the measurement of serum AGEs might identify individuals at high risk of cardiovascular complications among diabetic women.

Acknowledgements R. Bucala (Picower Research Institute, Manhasset, NY, USA) kindly supplied the anti-AGE antibodies. We thank T. Arnesen Siegwarth for skilful technical assistance. B. K. Kilhovd was supported by 
a research grant from the EXTRA funds from the Norwegian Foundation for Health and Rehabilitation, and by the Diabetes Research Centre (Aker and Ullevål University Hospitals). M. Laakso was supported by a grant from the Academy of Finland.

Duality of interest No duality of interest exists for any of the authors.

\section{References}

1. Brownlee M (1995) Advanced protein glycosylation in diabetes and aging. Annu Rev Med 46:223-234

2. Fu MX, Requena JR, Jenkins AJ, Lyons TJ, Baynes JW, Thorpe SR (1996) The advanced glycation end product, $N^{\varepsilon}$-(carboxymethyl)lysine, is a product of both lipid peroxidation and glycoxidation reactions. J Biol Chem 271:9982-9986

3. Schmidt AM, Vianna M, Gerlach M et al (1992) Isolation and characterization of two binding proteins for advanced glycosylation end products from bovine lung which are present on the endothelial cell surface. J Biol Chem 267:14987-14997

4. Vlassara H, Li YM, Imani F et al (1995) Identification of galectin3 as a high-affinity binding protein for advanced glycation end products (AGE): a new member of the AGE-receptor complex. Mol Med 1:634-646

5. Li YM, Mitsuhashi T, Wojciechowicz D et al (1996) Molecular identity and cellular distribution of advanced glycation endproduct receptors: relationship of p60 to OST-48 and p90 to $80 \mathrm{~K}-\mathrm{H}$ membrane proteins. Proc Natl Acad Sci U S A 93:11047-11052

6. Nakamura Y, Horii Y, Nishino T et al (1993) Immunohistochemical localization of advanced glycosylation end products in coronary atheroma and cardiac tissue in diabetes mellitus. Am J Pathol 143:1649-1656

7. Schmidt AM, Hori O, Chen JX et al (1995) Advanced glycation endproducts interacting with their endothelial receptor induce expression of vascular cell adhesion molecule-1 (VCAM-1) in cultured human endothelial cells and in mice. A potential mechanism for the accelerated vasculopathy of diabetes. J Clin Invest 96:1395-1403

8. Vlassara H, Fuh H, Donnelly T, Cybulsky M (1995) Advanced glycation endproducts promote adhesion molecule (VCAM-1, ICAM-1) expression and atheroma formation in normal rabbits. Mol Med 1:447-456

9. Bucala R, Makita Z, Koschinsky T, Cerami A, Vlassara H (1993) Lipid advanced glycosylation: pathway for lipid oxidation in vivo. Proc Natl Acad Sci U S A 90:6434-6438

10. Lyons TJ, Jenkins AJ (1997) Lipoprotein glycation and its metabolic consequences. Curr Opin Lipidol 8:174-180

11. Bucala R, Tracey KJ, Cerami A (1991) Advanced glycosylation products quench nitric oxide and mediate defective endotheliumdependent vasodilatation in experimental diabetes. J Clin Invest 87:432-438

12. Reddy S, Bichler J, Wells-Knecht KJ, Thorpe SR, Baynes JW (1995) $N^{\varepsilon}$-(carboxymethyl)lysine is a dominant advanced glycation end product (AGE) antigen in tissue proteins. Biochemistry 34:10872-10878

13. Kislinger T, Fu C, Huber B et al (1999) $N^{\varepsilon}$-(carboxymethyl)lysine adducts of proteins are ligands for receptor for advanced glycation end products that activate cell signaling pathways and modulate gene expression. J Biol Chem 274:31740-31749

14. Thornalley PJ, Battah S, Ahmed N et al (2003) Quantitative screening of advanced glycation endproducts in cellular and extracellular proteins by tandem mass spectrometry. Biochem J 375:581-592
15. Sims TJ, Rasmussen LM, Oxlund H, Bailey AJ (1996) The role of glycation cross-links in diabetic vascular stiffening. Diabetologia 39:946-951

16. Wolffenbuttel BH, Boulanger CM, Crijns FR et al (1998) Breakers of advanced glycation end products restore large artery properties in experimental diabetes. Proc Natl Acad Sci U S A 95:4630-4634

17. Kass DA, Shapiro EP, Kawaguchi M et al (2001) Improved arterial compliance by a novel advanced glycation end-product crosslink breaker. Circulation 104:1464-1470

18. Kiuchi K, Nejima J, Takano T, Ohta M, Hashimoto H (2001) Increased serum concentrations of advanced glycation end products: a marker of coronary artery disease activity in type 2 diabetic patients. Heart 85:87-91

19. Kilhovd BK, Juutilainen A, Lehto S et al (2005) High serum levels of advanced glycation end products predict increased coronary heart disease mortality in nondiabetic women but not in nondiabetic men: a population-based 18-year follow-up study. Arterioscler Thromb Vasc Biol 25:815-820

20. Laakso M, Rönnemaa T, Pyörälä K, Kallio V, Puukka P, Penttilä I (1988) Atherosclerotic vascular disease and its risk factors in noninsulin-dependent diabetic and nondiabetic subjects in Finland. Diabetes Care 11:449-463

21. The World Health Organization (1983) World Health Organization proposal for the multinational monitoring of trends and determinants in cardiovascular disease and protocol (MONICA Project). WHO/MNC/82.1 Rev. 1. WHO, Geneva

22. Walker AE, Robins M, Weinfeld FD (1981) The national survey of stroke. Clinical findings. Stroke 12(Suppl 1):I13-I44

23. Berg TJ, Bangstad HJ, Torjesen PA, Østerby R, Bucala R, Hanssen KF (1997) Advanced glycation end products in serum predict changes in the kidney morphology of patients with insulindependent diabetes mellitus. Metabolism 46:661-665

24. Makita Z, Vlassara H, Cerami A, Bucala R (1992) Immunochemical detection of advanced glycosylation end products in vivo. $\mathrm{J}$ Biol Chem 267:5133-5138

25. Kostner GM (1976) Letter: enzymatic determination of cholesterol in high-density lipoprotein fractions prepared by polyanion precipitation. Clin Chem 22:695

26. Friedewald WT, Levy RI, Fredrickson DS (1972) Estimation of the concentration of low-density lipoprotein cholesterol in plasma, without use of the preparative ultracentrifuge. Clin Chem 18:499-502

27. Cockcroft DW, Gault MH (1976) Prediction of creatinine clearance from serum creatinine. Nephron 16:31-41

28. Genuth S, Sun W, Cleary P et al (2005) Glycation and carboxymethyllysine levels in skin collagen predict the risk of future 10-year progression of diabetic retinopathy and nephropathy in the diabetes control and complications trial and epidemiology of diabetes interventions and complications participants with type 1 diabetes. Diabetes 54:3103-3111

29. Kilhovd BK, Berg TJ, Birkeland KI, Thorsby P, Hanssen KF (1999) Serum levels of advanced glycation end products are increased in patients with type 2 diabetes and coronary heart disease. Diabetes Care 22:1543-1548

30. Tan KC, Chow WS, Tam S, Bucala R, Betteridge J (2004) Association between acute-phase reactants and advanced glycation end products in type 2 diabetes. Diabetes Care 27:223-228

31. Boulanger E, Wautier MP, Wautier JL et al (2002) AGEs bind to mesothelial cells via RAGE and stimulate VCAM-1 expression. Kidney Int 61:148-156

32. Valencia JV, Mone M, Koehne C, Rediske J, Hughes TE (2004) Binding of receptor for advanced glycation end products (RAGE) ligands is not sufficient to induce inflammatory signals: lack of activity of endotoxin-free albumin-derived advanced glycation end products. Diabetologia 47:844-852 
33. Brownlee M (2001) Biochemistry and molecular cell biology of diabetic complications. Nature 414:813-820

34. Bucala R, Makita Z, Vega G et al (1994) Modification of low density lipoprotein by advanced glycation end products contributes to the dyslipidemia of diabetes and renal insufficiency. Proc Natl Acad Sci U S A 91:9441-9445

35. Cai W, He JC, Zhu L et al (2004) High levels of dietary advanced glycation end products transform low-density lipoprotein into a potent redox-sensitive mitogen-activated protein kinase stimulant in diabetic patients. Circulation 110:285-291

36. Berg TJ, Clausen JT, Torjesen PA, Dahl-Jørgensen K, Bangstad HJ, Hanssen KF (1998) The advanced glycation end product $N^{\varepsilon}$ (carboxymethyl)lysine is increased in serum from children and adolescents with type 1 diabetes. Diabetes Care 21:1997-2002

37. Kilhovd BK, Giardino I, Torjesen PA et al (2003) Increased serum levels of the specific AGE-compound methylglyoxal-derived hydroimidazolone in patients with type 2 diabetes. Metabolism $52: 163-167$

38. Juutilainen A, Kortelainen S, Lehto S, Rönnemaa T, Pyörälä K, Laakso M (2004) Gender difference in the impact of type 2 diabetes on coronary heart disease risk. Diabetes Care 27:2898-2904

39. Vlassara H, Cai W, Crandall J et al (2002) Inflammatory mediators are induced by dietary glycotoxins, a major risk factor for diabetic angiopathy. Proc Natl Acad Sci U S A 99:15596-15601

40. Kuller LH, Tracy RP, Shaten J, Meilahn EN (1996) Relation of Creactive protein and coronary heart disease in the MRFIT nested case-control study. Multiple Risk Factor Intervention Trial. Am J Epidemiol 144:537-547

41. Soinio M, Marniemi J, Laakso M, Lehto S, Rönnemaa T (2006) High-sensitivity C-reactive protein and coronary heart disease mortality in patients with type 2 diabetes: a 7-year follow-up study. Diabetes Care 29:329-333 